\title{
A Two-Stage Method for an Approximate Calculation of Statically Indeterminate Trusses
}

\author{
Janusz Rębielak \\ Faculty of Architecture, Cracow University of Technology, Kraków 31-155, Poland
}

\begin{abstract}
The paper presents the principles of a method, which in two simple stages makes possible to carry out the statically calculation of values of forces acting in the flat static indeterminate trusses. In each stage, it is considered the static determinate truss, scheme of which is obtained after remove the suitable number of members from the basic static indeterminate truss. The both intermediate statically determinate trusses are of the same clear span and they are loaded by forces of half values applied to the corresponding truss nodes. The method applies one of the typical procedures of calculation of the statically determinate trusses and then it is applied in an appropriate way the rule of superposition for obtaining the final values of forces acting in particular members of the basic truss. The values of forces calculated in this way are of a very close approximation to the force values determined in the special and complex ways being considered as the exact calculation methods. The proposed method can be useful mostly but not only for the initial structural design of such systems. The simplicity of the two-stage method justifies an assumption that it can be relatively easy and worthy to adjust to the requirements of the computer aided technology of statically calculation of the complex forms of trusses.
\end{abstract}

Key words: Method of static calculation, truss structure, static indeterminate truss, static determinate truss, rule of superposition.

\section{Introduction}

The structural systems of various trusses among others are very frequently applied as the main bearing systems of various types of roofs. They consist of straight members, which in the concentric way are connected together in theoretically articulated joints. Because the forces are transmitted along axes of struts, the truss system is relatively lightweight and it constitutes the effective support structure even for a large span cover. Simple trusses are usually statically determinate systems and for the needs of the calculation of the force values acting in their members one can apply an equally simple method like, e.g., the Cremona's method or the Ritter's method described in works [1-4]. More complex forms of the flat trusses are statically indeterminate systems, and in order to define the forces values, one should apply specific

Corresponding author: Janusz Rebielak, Ph.D., D.Sc., professor, research fields: architecture, numerical methods of shaping and design of the space structures, methods of static calculation, lightweight structures for large span roofs, tall buildings, foundation systems. E-mail: j.rebielak@wp.pl. methods, taking into account different stiffness of components creating these systems. Numerous specific methods, which are considered the elementary displacements, forces or the units of suitable energy are for the long time used for calculation of these structural systems. They are of quite complex structure and moreover they need the multiple repetitions of elementary calculations as it is presented in works [5-10]. In the last decades, there were developed a series of methods of calculations necessary for the structural design, which have been recently enormously accelerated by means of the appropriate software and suitable computer techniques. The proposed method makes possible to calculate the statically indeterminate truss in two simple stages by means of methods applied for calculations of the statically determinate trusses. It gives in result values of forces being very close to results obtained by means of the exact but complex method of calculations. 


\section{Concept of Proposed Method}

The presented method was invented during the initial statically analysis of a certain group of the tension-strut spatial structures meant to be the support structural systems for various types of the roof covers as presented in paper [11]. The external layers and vertical members of these structures are composed of the very slender steel elements while the cross braces are designed as struts, as shown in Fig. 1.

The simplified schemes of the typical vertical cross-sections of this group of structures, which have to be suitably pre-stressed, are shown in Fig. 2a.

The truss system of the assumed basic structural configuration is created by a number of nodes " $w$ " which equals 17 and the number of members " $p$ " is

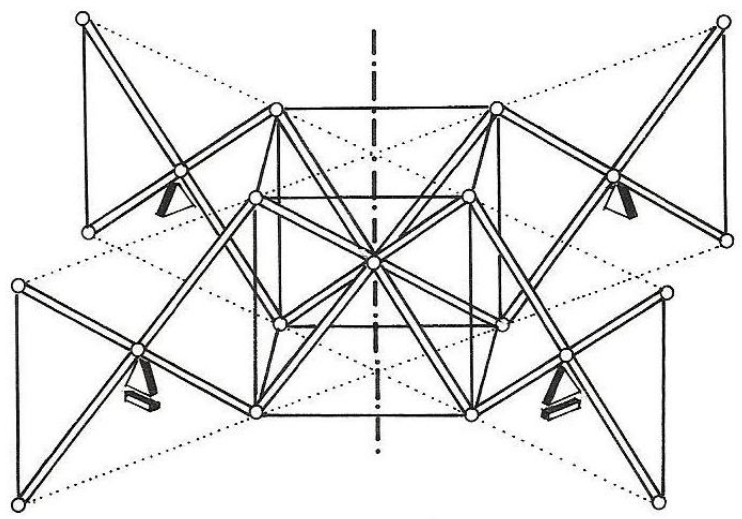

Fig. 1 Structural concept of a space tension-strut structure.

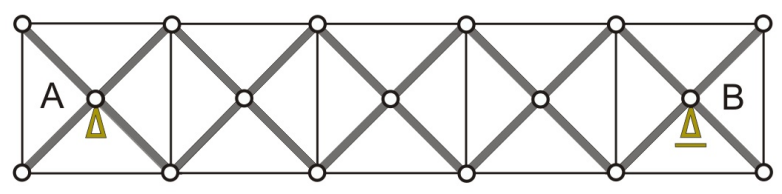

(a)

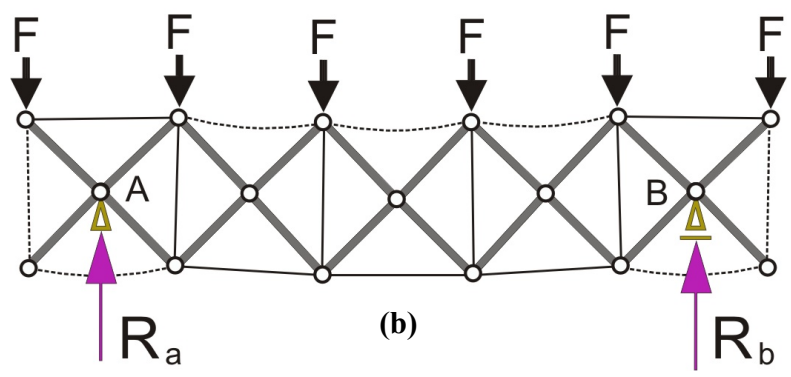

Fig. 2 Simplified schemes of vertical cross-sections. equal to 36. A statically determinate truss built by the same number of nodes $w=17$ has to consist of exactly $p=31$ members, what is defined by the condition of the inner statically determinacy of a truss

$$
p=2 \times w-3
$$

what gives in the result an above mentioned figure

$$
31=2 \times 17-3
$$

It means that the basic scheme represents the fivefold statically indeterminate plane truss. After applying the force values $F$, bigger than it is allowed, to the nodes of the upper chord one can notice that several tension members are excluded from the force transmission process to the supports $\mathrm{A}$ and $\mathrm{B}$ of this truss, as shown in Fig. 2b. It implies that the scheme in this drawing represents now a statically determinate truss, which implies further that under the same load the force values in particular members can be calculated by means of, for instance, the Cremona's method. This conclusion arises the following question: in what way could the statically indeterminate truss be calculated by means of a method used only for the statically determinate trusses? A suggestion for answering this question can be given after consideration of the arrangement of the active components of the truss shown in Fig. 2b. Pattern of the underwent deformation of the basic truss was the inspiration for invention of the two-stage method of calculation of the statically indeterminate trusses, which took place during the initial calculations of the selected type of the tension-strut structures and is demonstrated in the following works $[12,13]$. From the general conditions of equilibrium follows that the sought after the required calculation procedure has to be done in two separated stages, schemes of which are presented in Fig. 3. The considered truss consists only of struts and it is loaded by forces $F$ applied to each node of the upper chord. In the first stage, it is proposed to remove all these members, which are situated in position of components that in the tension-strut structure were excluded from the force transmission process, compared with Fig. $2 b$. 


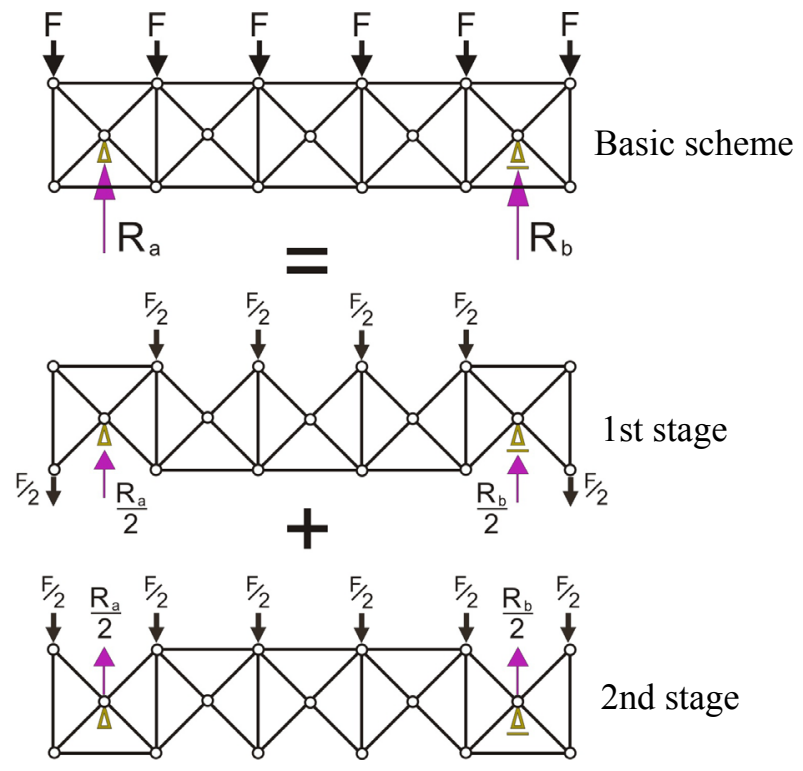

Fig. 3 Scheme of stages of the proposed method.

The number of removed members has to be, and in fact really is, equal to the degree of statically indeterminacy of this basic truss. The truss of the reduced number of members has to be loaded by forces of half the value of force $F$ applied to suitable nodes. In the second stage, one should reject the same number of members but this time, positioned oppositely and symmetrically towards the longitudinal axis of the basic truss and like previously to apply load forces of half the value of $F$ to the corresponding nodes. In each stage, the clear spans of the calculated trusses are the same. The final force values will be obtained as results of a suitable application of the rule of superposition. It means that the final value of the force acting in a particular member of the basic statically indeterminate truss will be the resultant of the force vectors calculated for the corresponding member in each stage. This remark refers also to members, which counterparts were rejected in each of the two stages. The proposed calculation method can be made in several different ways or in various procedures. Schemes of another simple procedure are presented on the right side of Fig. 4.

In this case, during the first stage, are removed the appropriate number of members from the upper chord.
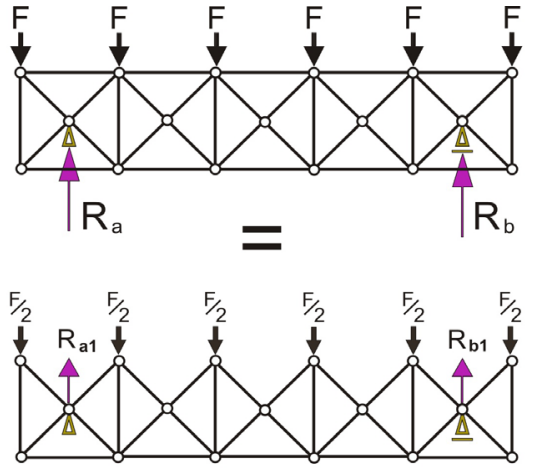

$+$

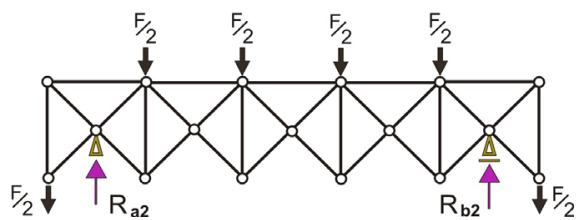

Fig. 4 Another scheme of proposed calculation procedure.

In the second stage, the same number of members is removed from the lower chord of the basic truss. The details of the all particular steps of the calculation procedure remain the same, like it was described above.

\section{Comparison of Force Values Obtained by Two Different Methods of Calculations}

In order to verify the correctness of the taken assumptions, the static calculations were carried out by means of the proposed two-stage method and by the application of one of the appropriate methods used by the computer software ICES-STRUDL, which is presented in Refs. [13-15]. Both of the calculations were made for the same plane truss of the static scheme presented in Fig. 5. All the structural features, including the boundary conditions and way of support together with the localization of nodes, to which are applied equal forces, are assumed as the same.

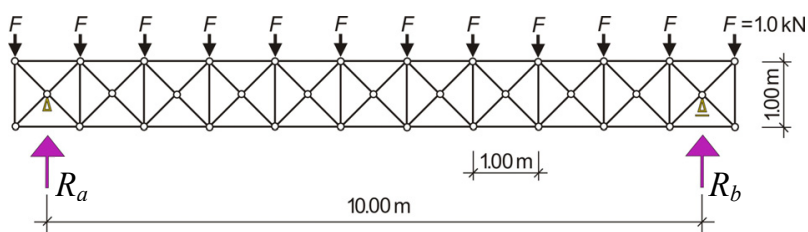

Fig. 5 Shape of a plane statically indeterminate truss being calculated in the both compared methods. 
The investigated truss has parallel chords, its construction depth equals $1.00 \mathrm{~m}$, the clean span is equal to $10.00 \mathrm{~m}$ and the whole structure consists of steel members of the same Young's module $(E)$ and an equal area of the principal cross-sections and the same value of the moment of inertia $(I)$. The truss scheme and the polygon of forces together with the force values obtained in the first stage of these calculations are presented in Fig. 6.

Because the truss is symmetrical and it is loaded in a symmetric way that is why the results of the all calculations are presented only for its half. The truss is built by a total number of nodes $w=35$ and number of members $p=78$. In this case, the condition of the inner statically determinacy of a truss in criteria of Eq. (1) takes the following form:

A

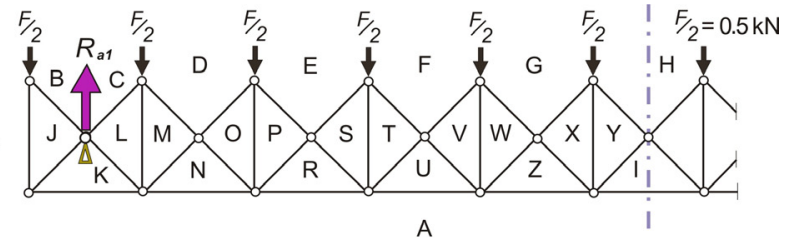

$$
\begin{array}{lll}
S_{A J}=-0.500 \mathrm{kN} & S_{D O}=-4.242 \mathrm{kN} & S_{F T}=-6.363 \mathrm{kN} \\
S_{B J}=0.000 \mathrm{kN} & S_{O N}=-1.414 \mathrm{kN} & S_{T U}=-7.778 \mathrm{kN} \\
S_{J K}=+0.707 \mathrm{kN} & S_{O P}=+5.500 \mathrm{kN} & S_{F V}=-7.778 \mathrm{kN} \\
S_{C L}=-1.414 \mathrm{kN} & S_{E P}=-4.242 \mathrm{kN} & S_{V U}=-6.363 \mathrm{kN} \\
S_{L K}=+2.121 \mathrm{kN} & S_{P R}=-6.363 \mathrm{kN} & S_{V W}=+10.500 \mathrm{kN} \\
S_{L M}=+1.500 \mathrm{kN} & S_{E S}=-6.363 \mathrm{kN} & S_{G W}=-7.778 \mathrm{kN} \\
S_{D M}=-1.414 \mathrm{kN} & S_{S R}=-4.242 \mathrm{kN} & S_{W Z}=-8.485 \mathrm{kN} \\
S_{M N}=-4.242 \mathrm{kN} & S_{S T}=+8.500 \mathrm{kN} & S_{G X}=-8.485 \mathrm{kN} \\
S_{K A}=-0.500 \mathrm{kN} & S_{N A}=+4.000 \mathrm{kN} & S_{R A}=+7.500 \mathrm{kN} \\
S_{Z A}=+11.500 \mathrm{kN} & S_{X Z}=-7.778 \mathrm{kN} & S_{X Y}=+11.500 \mathrm{kN} \\
S_{U A}=+10.000 \mathrm{kN} & & \\
S_{I A}=+12.000 \mathrm{kN} & Y & S_{H Y}=-8.485 \mathrm{kN} \\
& & S_{Y I}=-8.485 \mathrm{kN}
\end{array}
$$

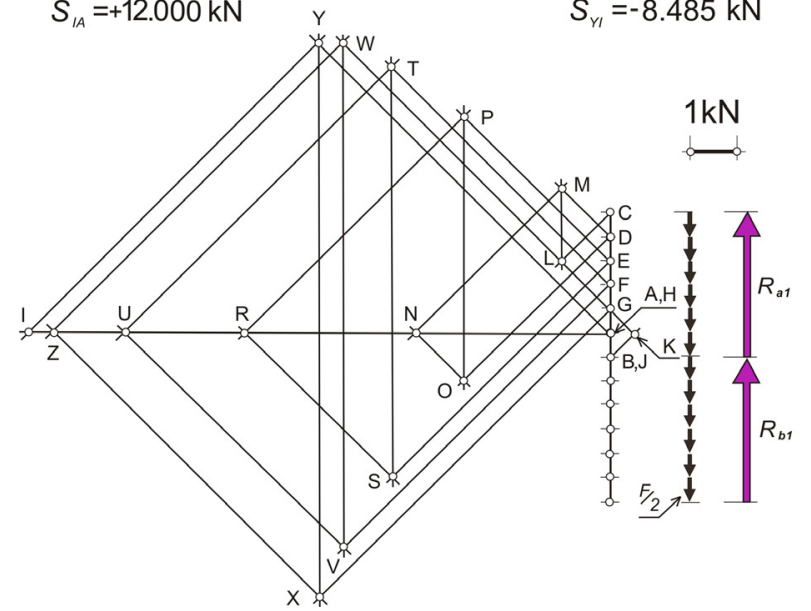

Fig. 6 Results of the first stage of calculations.

$$
67=2 \times 35-3
$$

This value indicates that it is an eleven-fold statically indeterminate truss. In the presented example of the two-stage method, the Cremona's method is used. In the first stage eleven members of the upper chord are removed, while in the second stage the same numbers of members are removed from the lower chord, as shown in Fig. 7. In both stages, the load forces are applied only to nodes of the upper chord.

In the first stage, the force value defined for a selected member, placed for instance between areas $D$ and $M\left(S_{D M}\right)$, equals to $-1.414 \mathrm{kN}$, as shown in Fig. 6 , which means that in this structural configuration it is a compression member. In the second stage, a member of the same position, as shown in Fig. 7, is subjected
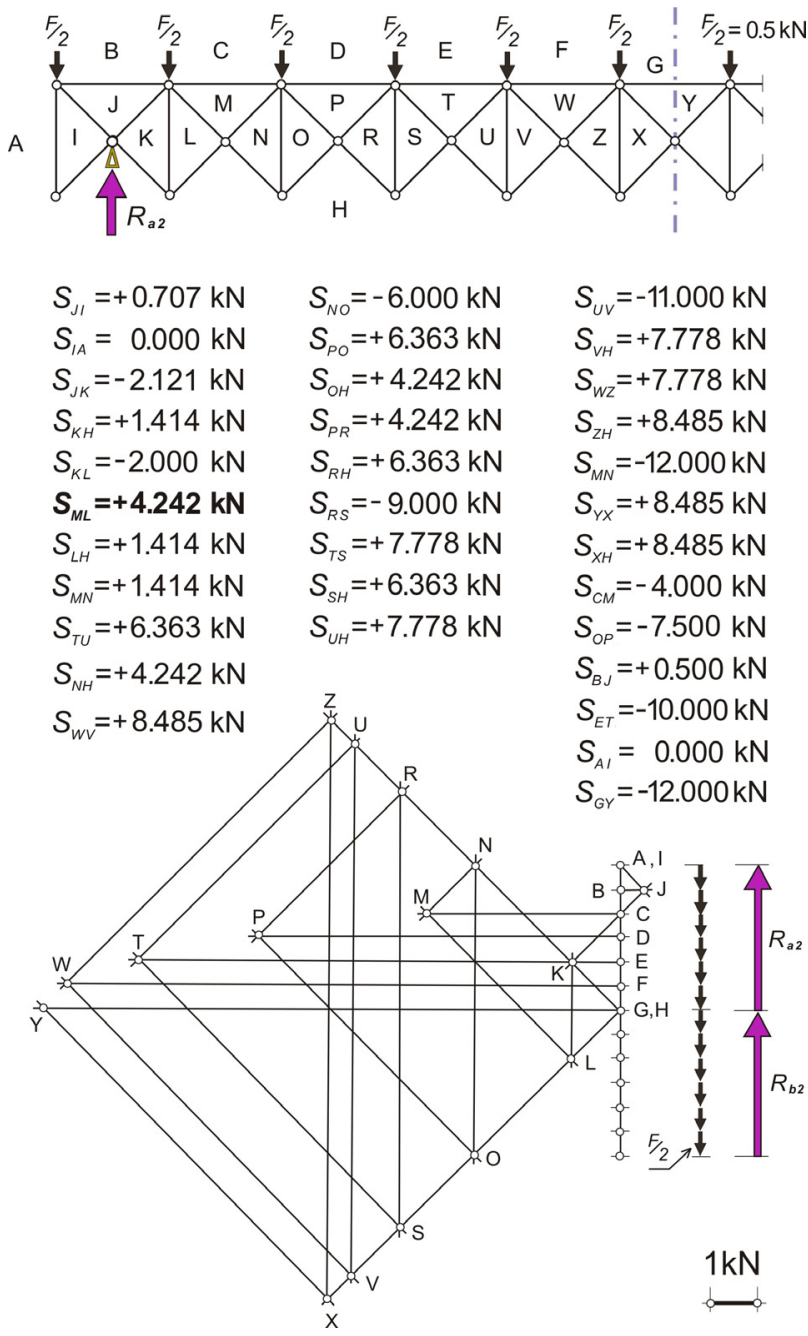

Fig. 7 Results of the second stage of calculations. 
to act of the tension force $\left(S_{M L}\right)$, which value is equal to $+4.242 \mathrm{kN}$. The value of the force acting in the corresponding member in the basic structure, comparing with Fig. 8, is obtained as a resultant of both these vector values and it equals ca. $+2.83 \mathrm{kN}$.

The simple rule of superposition is applied for all members of the calculated truss. For example, the value of the force vector acting in the central member of the lower chord calculated in the first stage $\left(S_{I A}\right)$ equals $+12.00 \mathrm{kN}$, as shown in Fig. 6. In the second stage, the member being a counterpart to the considered one is removed, so in this case the force has a zero value. It is obvious that after application the simple rule of superposition, the resultant force value in the central member of the lower chord is equal to $+12.00 \mathrm{kN}$. The sizes of forces acting in the members of this part of the basic truss are presented in Fig. $8 \mathrm{~b}$ visually. The results obtained in the method suitable for calculation of the statically indeterminate trusses and carried out by the application of the computer software ICES-STRUDL for the same part of the truss are shown in Fig. 9. Force values defined in these computer aided calculations are considered as the exact forces acting in the truss members [13]. It is easy to notice some differences between the force values calculated in both methods for the same truss member.

For example in this exact method, the force value calculated for the considered cross brace equals $+2.708 \mathrm{kN}$ while in the two-stage method the calculated value is equal to $+2.83 \mathrm{kN}$. The proposed two-stage method uses procedures appropriate for the calculation of the statically determinate trusses which implies that in its procedures we do not take into consideration the differences between stiffness of components jointed in each of the common nodes. Therefore, the two-stage method can give only an approximation of the force values calculated for each particular member. From the analysis of both groups of results follows that the differences are relatively small in comparison to the total force value acting in
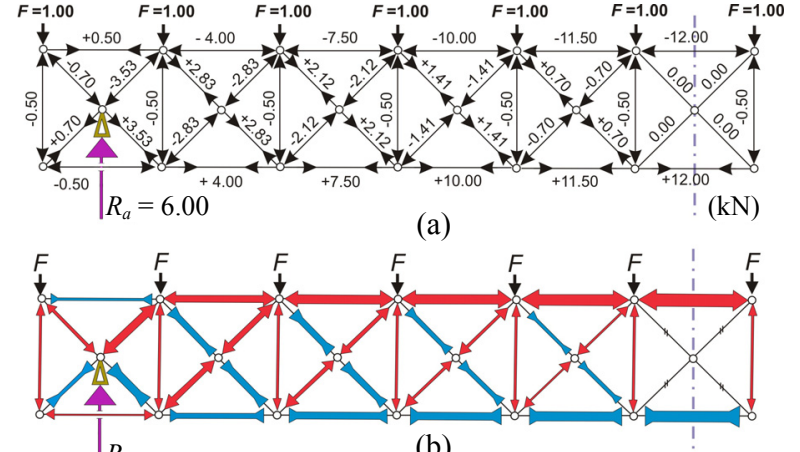

Fig. 8 (a) Final values of forces calculated in the proposed two-stage method for each member of the half truss; (b) visual presentation of force sizes acting in this part of the calculated truss.

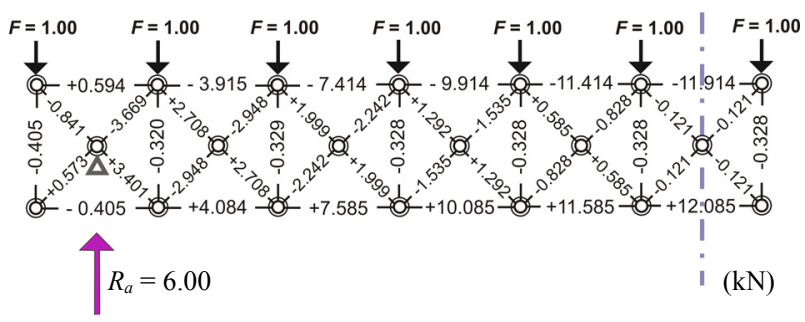

Fig. 9 Values of forces obtained for the same part of truss by application of one of the standard methods with the help of computer aided technology.

the particular member. The small differentiation can be to some degree explained by the relatively small variety of lengths of members creating the truss. Nevertheless, one can recognize that the two-stage method gives in result quite good approximate values of forces acting in the plane statically indeterminate trusses.

\section{Conclusions}

The proposed two-stage method of calculation of the statically indeterminate trusses gives results that closely approximate the real values of forces acting in their members. Therefore, it can be applied for the preliminary structural design of such systems. These results are obtained by applications of much easier and simpler calculation procedures than those used in the exact methods. The accuracy of the results obtained in this way can be in the future enhanced by taking into consideration the differences of stiffness of members connected in the nodes through application 
of suitably defined individual coefficients and iteration procedures. One should expect that the two-stage method can be easily adapted to the requirements of computer aided techniques of the structural design. This is why the next anticipation may be justified that in the future it could be to some degree competitive to the methods usually applied for calculation of the statically indeterminate trusses.

\section{Acknowledgments}

The author expresses his gratitude to Prof. W.J. Beranek and Prof. G.J. Hobbelman from the Delft University of Technology in the Netherlands for the support in processes of the computer calculations necessary for this research.

\section{References}

[1] T. Kolendowicz, Theory of Structures for Architects, Arkady, Warszawa, 1993. (in Polish)

[2] S. Pyrak, K. Szulborski, Structural Mechanics for Architects, Examples of Calculations, Arkady, Warszawa, 1994. (in Polish)

[3] J. Przewłócki, J. Górski, Basis of Theory of Structures, Arkady, Warszawa, 2006. (in Polish)

[4] E. Allen, W. Zalewski, Boston Structures Group, Form and Forces, Designing Efficient, Expressive Structures, John Wiley \& Sons Inc., Hoboken, New Jersey, 2010.

[5] S.P. Timoshenko, History of Strength of Materials, Arkady, Warszawa, 1966. (in Polish)
[6] W. Nowacki, Theory of Structures, State Scientific Publishing House, Warszawa, 1960. (in Polish)

[7] Z.S. Makowski, Analysis, Design and Construction of Double-Layer Grids, Applied Science Publishers, London, 1981.

[8] Z. Dylag, E. Krzemińska-Niemiec, F. Filip, Theory of Structures, State Scientific Publishing House, Warszawa, 1989. (in Polish)

[9] O.C. Zienkiewicz, R.L. Taylor, The Finite Element Method, Oxford Press, UK, 2000.

[10] T. Lewiński, On algebraic equations of elastic trusses, frames and grillages, Journal of Theoretical and Applied Mechanics 39 (2) (2001) 307-322.

[11] J. Rębielak, Spatial tension-strut structures, Bearing Structures of the Shell Covers Architektura 1 (1983) 69-70. (in Polish)

[12] J. Rębielak, Two-Stage Method of Calculation of Statically Indeterminate Trusses, Project No. 4.1.2.1, Faculty of Architecture Technical University Delft, The Netherlands, 1985. (in Polish)

[13] J. Rębielak, W.J. Beranek, G.J. Hobbelman, Multi-layer Space Structures: Static and Geometrical Problems, Scientific report of Institute of Architecture and Town Planning, Wroclaw University of Technology, Poland, 1985. (in Polish)

[14] J. Rębielak, A method of static calculation and shape of structural system developed by application of principles of superposition: Lightweight structures in civil engineering: Contemporary problems, in: Local Seminar of IASS Polish Chapter, Warsaw, 2012, pp. 155-158.

[15] J. Rębielak, Method of calculation of statically indeterminate trusses in two stages, Mechanik 86 (7) (2013) 729-736. (in Polish) 